\title{
$\left.{ }_{\{S C I E N C E}^{[M A T R X}\right\}$ Mascot Search Results
}

\section{Protein View}

Match to: FLID_SALTY Score: 98 Expect: 1.9e-006

Flagellar hook-associated protein 2 OS=Salmonella typhimurium (strain LT2 / SGSC1412/ ATCC 700720 ) GN=fliD PE=1 SV=2

Nominal mass $\left(\mathrm{M}_{\mathrm{r}}\right)$ : 49805; Calculated pI value: $\mathbf{5 . 2 7}$

NCBI BLAST search of FLID SALTY against $\mathrm{nr}$

Unformatted sequence string for pasting into other applications

Taxonomy: Salmonella enterica subsp. enterica serovar Typhimurium str. LT2

Variable modifications: Carbamidomethyl (C), Oxidation (M)

Cleavage by Trypsin: cuts C-term side of KR unless next residue is $P$

Number of mass values searched: $\mathbf{5 0}$

Number of mass values matched: 13

Sequence Coverage: $36 \%$

Matched peptides shown in Bold Red

1 MASISSLGVG SNLPLDQLLT DLTKNEKGRL TPITKQQSAN SAKLTAYGTL

51 KSALEKFQTA NTALNKADLF KSTVASSTTE DLKVSTTAGA AAGTYKINVT

101 QLAAAOSLAT KTTFATTKEQ LGDTSVTSRT IKIEQPGRKE PLEIKLDKGD

151 TSMEAIRDAI NDADSGIAAS IVKVKENEFO LVLTANSGTD NTMKITVEGD

201 TKLNDLLAYD STTNTGNMQE LVKAENAKLN VNGIDIERQS NTVTDAPQGI

251 TLTLTKKVTD ATVTVTKDDT KAKEAIKSWV DAYNSLVDTF SSLTKYTAVE

301 PGEEASDKNG ALLGDSVVRT IOTGIRAOFA NSGSNSAFKT MAEIGITODG

351 TSGKLKIDDD KLTKVLKDNT AAARELLVGD GKETGITTKI ATEVKSYLAD

401 DGIIDNAQDN VNATLKSLTK QYLSVSNSID ETVARYKAQF TQLDTMMSKL

451 NNTSSYLTQQ FTAMNKS

Show predicted peptides also

Sort Peptides By $\odot$ Residue Number $\bigcirc$ Increasing Mass $\bigcirc$ Decreasing Mass

$\begin{array}{rrrr}\text { Start - End } & \text { Observed } & \text { Mr (expt) } & \text { Mr (calc) } \\ 57-66 & 1107.5593 & 1106.5520 & 1106.5720 \\ 97-111 & 1528.8756 & 1527.8684 & 1527.8620 \\ 174-194 & 2339.1859 & 2338.1786 & 2338.1475 \\ 174-194 & 2355.1866 & 2354.1793 & 2354.1424 \\ 229-238 & 1142.6248 & 1141.6176 & 1141.6091 \\ 258-271 & 1493.7333 & 1492.7260 & 1492.7621 \\ 278-295 & 2032.9860 & 2031.9787 & 2031.9789 \\ 309-319 & 1100.6029 & 1099.5956 & 1099.5986 \\ 320-326 & 788.4559 & 787.4487 & 787.4552 \\ 327-339 & 1328.6267 & 1327.6194 & 1327.6157 \\ 396-416 & 2250.1251 & 2249.1178 & 2249.0811 \\ 421-435 & 1681.8403 & 1680.8330 & 1680.8319 \\ 436-449 & 1707.7696 & 1706.7623 & 1706.8008\end{array}$

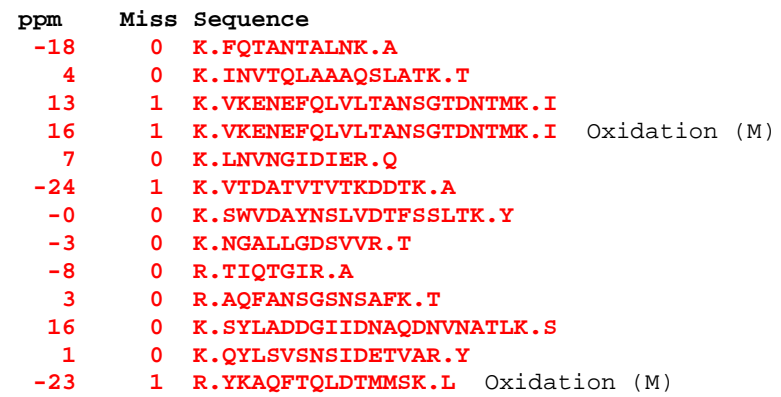

No match to: $628.0453,644.0066,650.0311,662.2878,666.0072,832.2875,833.0613,855.0439,870.5380,871.0200,973.5341$,
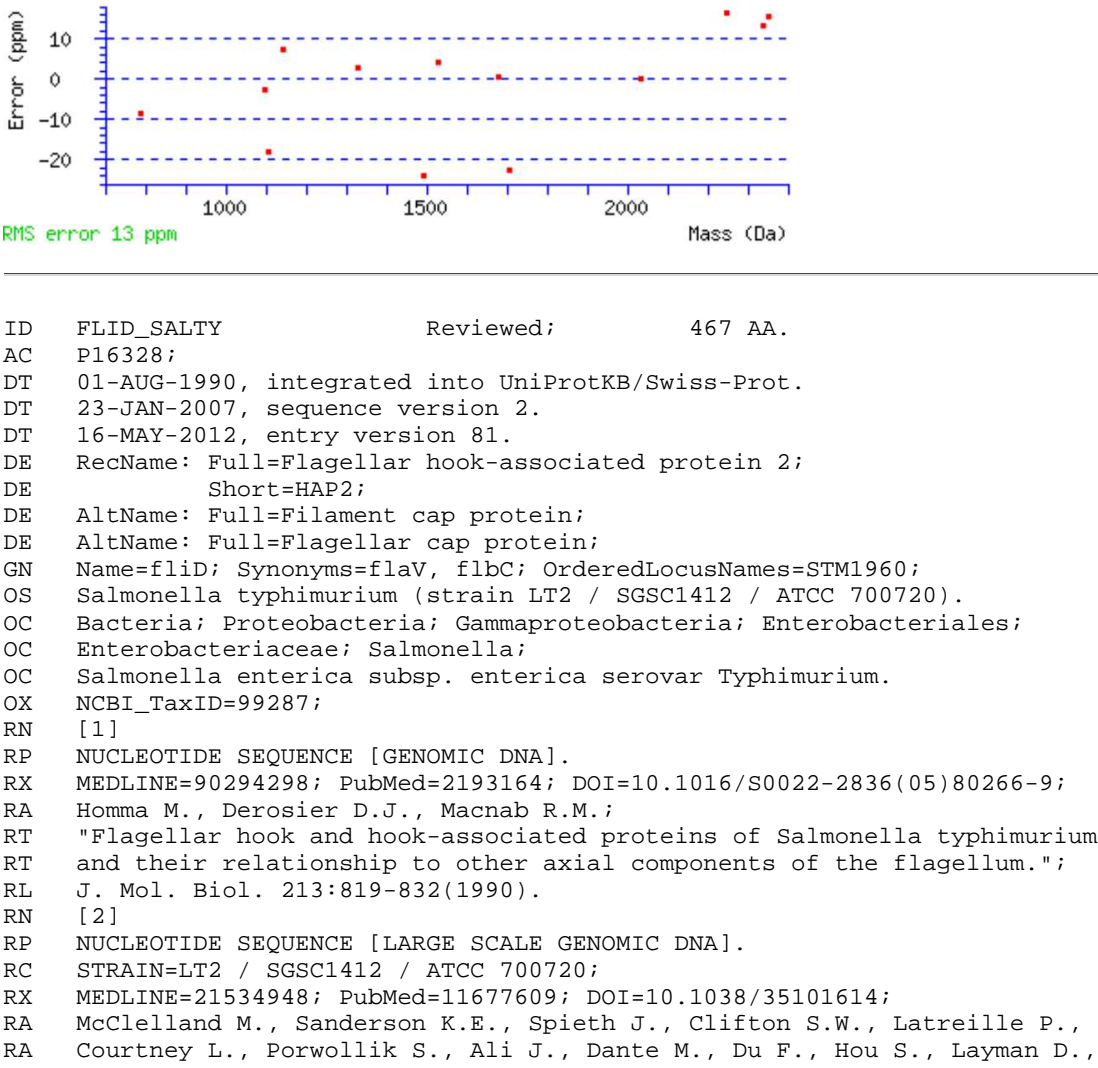

467 AA.

01-AUG-1990, integrated into UniProtKB/Swiss-Prot.

23-JAN-2007, sequence version 2.

16-MAY-2012, entry version 81.

RecName: Full=Flagellar hook-associated protein 2; Short $=$ HAP 2

AltName: Full=Filament cap protein;

AltName: Full=Flagellar cap protein

Name=fliD; Synonyms=flaV, flbC; OrderedLocusNames=STM1960,

Salmonella typhimurium (strain LT2 / SGSC1412 / ATCC 700720).

Bacteria; Proteobacteria; Gammaproteobacteria; Enterobacteriales;

Enterobacteriaceae; Salmonella;

Salmonella enterica subsp. enterica serovar Typhimurium.

NCBI_TaxID $=99287$.

[1]

NUCLEOTIDE SEQUENCE [GENOMIC DNA].

MEDLINE=90294298; PubMed=2193164； DOI=10.1016/S0022-2836(05) 80266-9;

Homma M., Derosier D.J., Macnab R.M.;

"Flagellar hook and hook-associated proteins of Salmonella typhimurium

and their relationship to other axial components of the flagellum.";

J. Mol. Biol. 213:819-832 (1990).

[2]

NUCLEOTIDE SEQUENCE [LARGE SCALE GENOMIC DNA].

STRAIN=LT2 / SGSC1412 / ATCC 700720;

MEDLINE=21534948; PubMed=11677609; DOI=10.1038/35101614;

McClelland M., Sanderson K.E., Spieth J., Clifton S.W., Latreille P.,

Courtney L., Porwollik S., Ali J., Dante M., Du F., Hou S., Layman D., 


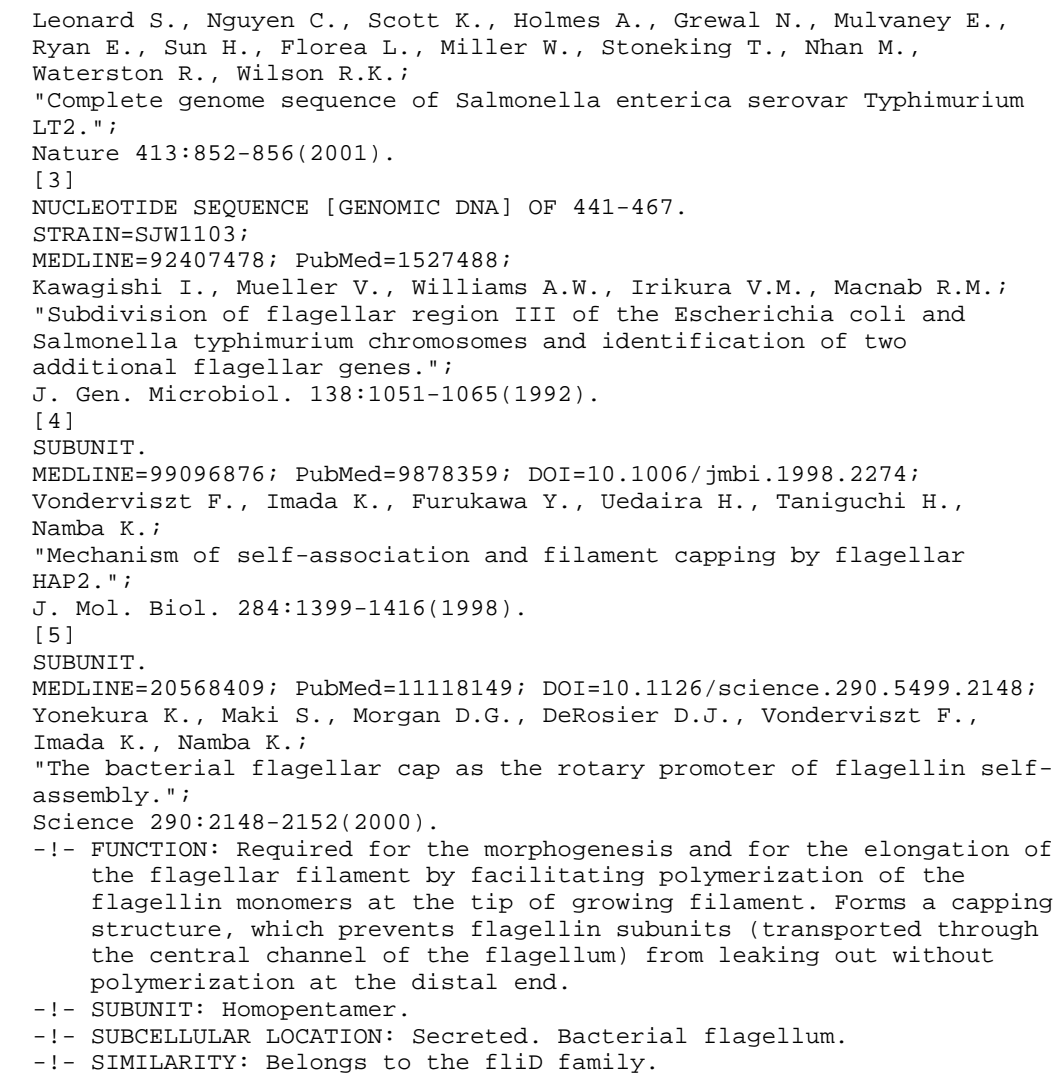

Copyrighted by the Uniprot Consortium, see http://www.uniprot.org/terms Distributed under the Creative Commons Attribution-NoDerivs License 